\title{
Fakor Determinan yang Memengaruhi Budaya Keselamatan Pasien di RS Pemerintah Kabupaten Kuningan
}

\author{
Lia Mulyati, Dedy Rachman, Yana Herdiana \\ STIKes Kuningan, Jawa Barat \\ Email:lia_mulyati@rocketmail.com
}

\begin{abstract}
Abstrak
Budaya keselamatan merupakan kunci untuk mendukung tercapainya peningkatan keselamatan dan kesehatan kerja dalam organisasi. Upaya membangun budaya keselamatan merupakan langkah pertama dalam mencapai keselamatan pasien. Terdapat beberapa faktor yang berkontribusi dalam perkembangan budaya keselamatan yaitu; sikap baik individu maupun organisasi, kepemimpinan, kerja tim, komunikasi dan beban kerja. Penelitian ini bertujuan mengetahui faktor determinan yang berhubungan dengan terciptanya budaya keselamatan pasien di RS Pemerintah Kabupaten Kuningan. Teknik pengambilan sampel yang digunakan incidental sampling 88 orang perawat pelaksana. Rancangan penelitian menggunakan survey analitik dengan pendekatan cross sectional, uji hipotesis digunakan Chi Square dan regresi logistik ganda. Hasil penelitian menunjukan terdapat pengaruh yang signifikan antara persepsi terhadap manajemen (p 0.0005, odd rasio 21.3), dukungan tim kerja (p 0.0005, odd rasio 13.34), stress kerja (p 0.006, odd rasio 3.94), kepuasan kerja (nilai p 0. 002) dengan budaya keselamatan pasien. Tidak terdapat pengaruh yang signifikan kondisi kerja dengan budaya keselamatan pasien dengan nilai $\mathrm{p}$ 0.507. Berdasarkan analisis multuvariat diperoleh persepsi terhadap manajemen menjadi factor determinan dengan nilai p $0.000<\alpha$ 0.05. Simpulan; unsur pimpinan memiliki pengaruh yang signifikan dalam menciptakan budaya keselamatan pasien. Pimpinan memiliki kewenangan dalam menerapkan system yang berlaku dalam organisasi, oleh karena itu gaya kepemimpinan, teknik komunikasi serta kemampuan manajerial merupakan suatu hal yang sangat perlu diperhatikan dalam menciptakan atmosfer kerja yang kondusif sebagai upaya terciptanya budaya keselamatan pasien. Berdasarkan hasil penelitian bahwa model kepemimpinan transformasional merupakan model yang sesuai diterapkan untuk meningkatkan budaya keselamatan pasien, pelatihan keterampilan komunikasi efektif serta pengembangan model pendidikan antar profesi sebagai upaya peningkatan kemampuan kolaborasi.
\end{abstract}

Kata kunci: Budaya keselamatan pasien, stress kerja, kepuasan kerja.

\section{Determinant factors that are Influencing Patient Safety Culture in a Government-owned Hospitals in Kuningan Regency}

\begin{abstract}
Safety culture is a key to support the achievement of occupational health and safety in an organization. An effort to build safety culture is the first step in ensuring patient safety. There are some factors that contribute in the development of safety culture, namely, individual and organizational attitude, leadership, team work, communication, and work load. This study aimed to identify the determinant factors that are related to achievement of patient safety culture in a government-owned hospital in Kuningan Regency. Eighty eight samples of nurses were recruited using incidental sampling technique. The research design was using cross sectional study, the hypothesis testing were using Chi Square and multiple logistic regression. The results showed that there were significant influenced between perception towards management $(\mathrm{p}=0.0005$, odd rasio 21.3), team work support $(p=0.0005$, odd rasio 13.34), work-related stress $(p=0.006$, odd rasio 3.94), work satisfaction $(p=0$. 002) with patient safety culture. There was not significant influenced between work condition and patient safety $(p=$ 0.507). The multivariate analysis showed that perception towards management was the determinant factor for patient safety culture $(\mathrm{p} 0.000<\alpha 0.05)$. In conclusion, leaders have significant influence in creating patient safety culture. Leaders have authority to implement systems in the organization. Therefore, leadership style, communication technique, and managerial ability are important in order to create a conducive atmosphere for developing patient safety culture. As recommendation, transformational leadership is a model that is appropriate to be applied in order to increase patient safety culture, trainings of effective communication and interprofessional education model are also needed to increase the collaboration skills among health professionals.
\end{abstract}

Keywords: Patient safety culture, work-related stress, work satisfaction. 
Lia Mulyati : Faktor Determinan yang Memengaruhi Budaya Keselamatan Pasien di RS

\section{Pendahuluan}

Keselamatan pasien (patient safety) merupakan isu penting dan global dalam pelayanan kesehatan. Isutersebut sudahmenjadiperhatian sejak tahun 1990an dan semakin menjadi perhatian sejak adanya laporan dari Institute of Medicine (IOM) tahun 1999 (dalam James. JT 2013), menyatakan bahwa di Amerika Serikat diproyeksikan terjadi 44.000 sampai dengan 98.000 kematian setiap tahun akibat dari medical error yang sebenarnya dapat dicegah. Data Kejadian Tidak Diharapkan di Indonesia sendiri masih sulit diperoleh secara lengkap dan akurat, tetapi dapat diasumsikan tidaklah kecil (KKP-RS, 2007).

Keselamatan pasien (patient safety) merupakan sistem rumah sakit yang membuat asuhan pasien lebih aman, mencegah terjadinya cedera yang disebabkan oleh kesalahan tindakan atau tidak mengambil tindakan yang seharusnya dilakukan. European Society (2006) dalam report for Methodes and Measures Working Group of WHO patient safety (2009), menyatakan budaya keselamatan pasien merupakan integrasi pola individu dan perilaku organisasi didasari oleh keyakinan dan nilai-nilai untuk meminimalkan kondisi yang membahayakan pasien secara terus menerus.

Colla et al, (2005) mengungkapkan bahwa tujuan dari budaya keselamatan kerja adalah ; (1) menghasilkan norma-norma perilaku,(2) mengurangi kecelakaan dan cedera, (3) memastikan bahwa isu tentang keselamatan pasien menjadi perhatian seluruh anggota organisasi, (4) meningkatkan kemampuan anggota organisasi untuk saling berbagi ideide dan keyakinan tentang risiko, kecelakan dan kondisi perburukan kesehatan, (5) meningkatkan komitmen masyarakat tentang keselamatan, (6) menentukan gaya dan kemampuan merancang program kesehatan dan keselamatan organisasi. Colla et al (2005) menyatakan organisasi dengan budaya positif dikarakteristikan dengan adanya komunikasi yang saling percaya, saling berbagi persepsi tentang pentingnya keselamatan dan adanya keyakinan terhadap kemampuan melakukan tindakan pencegahan.

Budaya keselamatan merupakan kunci untuk mendukung tercapainya peningkatan keselamatan dan kesehatan kerja dalam organisasi (KKP-RS 2007). Upaya menciptakan atau membangun budaya keselamatan merupakan langkah pertama dalam mencapai keselamatan pasien, seperti halnya yang tercantum dalam "Tujuh Langkah Menuju Keselamatan Pasien Rumah Sakit" di Indonesia, yaitu membangun budaya keselamatan pasien, memimpin dan mendukung staf, mengintegrasikan kegiatankegiatan manajemen risiko, meningkatkan kegiatan pelaporan, melibatkan dan berkomunikasi dengan pasien, belajar dan berbagi pengalaman tentang keselamatan pasien serta menerapkan solusi-solusi untuk mencegah cedera (KKP-RS 2007). Budaya keselamatan dibangun oleh berbagai faktor (dimensi), menurut NHS (2010) dimensi budaya keselamatan adalah kepemimpinan, kerja tim, komunikasi, beban kerja dan sistem keamanan.

Rumah Sakit Pemerintah Kabupaten Kuningan merupakan rumah sakit pemerintah tipe B, yang dijadikan sebagai pusat pelayanan kesehatan masyarakat Kuningan, Ciamis dan Majalengka, dengan rata-rata BOR 90-95\% untuk setiap ruangannya. Selain itu RS ini juga dijadikan sebagai lahan praktek mahasiswa kesehatan sewilayah III Cirebon dengan jumlah praktikan dalam satu shift di satu ruangan rata-rata $6-10$ orang, tentunya dengan jumlah pasien dan praktikan yang begitu banyak dengan latar belakang institusi yang beragam tidak menutup kemungkinan untuk terjadinya kejadian yang tidak diharapkan atau kejadian nyaris cedera, hal ini dibuktikan dengan terjadinya beberapa kesalahan dalam pemberian obat dan tindakan prosedur invasif yang dilakukan oleh mahasiswa pada masa praktik klinik mahasiswa periode bulan Oktober - Desember 2013. Hal tersebut terjadi karena kurangnya pengawasan dan koordinasi antara perawat dan clinical instructur dengan mahasiswa. Kejadian nyaris cedera atau kejadian yang tidak diharapkan yang pernah terjadi berdasarkan hasil observasi peneliti dalah terjadinya sepsis pada beberapa pasien post operasi, pasien jatuh di kamar mandi, kelemahan motorik ekstremitas bawah pasca operasi dengan anestesi lumbal, kegagalan pasein dan keluarga dalam mengambil keputusan akibat kurangnya informasi dari tim pemberi pelayanan kesehatan. Hal lain yang berisiko mengancam keselamatan 
Lia Mulyati : Faktor Determinan yang Memengaruhi Budaya Keselamatan Pasien di RS

pasien adalah kurangnya fasilitas pendukung pelaksanaan asuhan keperawatan seperti alat ganti balutan sehingga satu set balutan digunakan untuk beberapa pasien, tidak ada ruang khusus penyimpanan obat sehingga penyimpanan dan persiapan pemberian obat dilakukan di nurse station, bercampur dengan buku rekam medik pasien dan peralatan lainnya.

Hal paling mendasar di rasakan dapat mempengaruhi keselamatan pasien yang diungkapkan oleh kepala ruangan bedah kelas 3 adalah beban kerja perawat yang berlebihan, untuk dinas pagi perawat yang berdinas hanya 3 orang ditambah kepala ruangan sedangkan untuk dinas sore dan malam hanya 2 orang dengan jumlah rata-rata pasien 30 orang. Berdasarkan hasil wawancara dengan salah satu petugas kesehatan di RS, kejadian yang tidak diharapkan sendiri tidak pernah ada pelaporan secara aktual, dan hanya menjadi bahan perbincangan dikalangan petugas kesehatan di tempat kejadian. Berdasarkan hasil rekapitulasi angket yang diisi oleh pasien dan keluarga pasien rata-rata tingkat kepuasan pasien di ruang rawat inap berada pada rentang $65-70 \%$ dan hal tersebut masih kurang dari yang ditargetkan oleh pihak manajemen.

Kondisi tersebut membuat penulis tertarik untuk melakukan survei tentang budaya keselamatan pasien di Rumah Sakit Pemerintah Kabupaten Kuningan. Hasil penelitian ini dapat digunakan oleh rumah sakit sebagai acuan untuk menyusun strategi dalam upaya meningkatkan kualitas asuhan dan meningkatkan keselamatan pasien.

\section{Diagram Alur Penelitian}

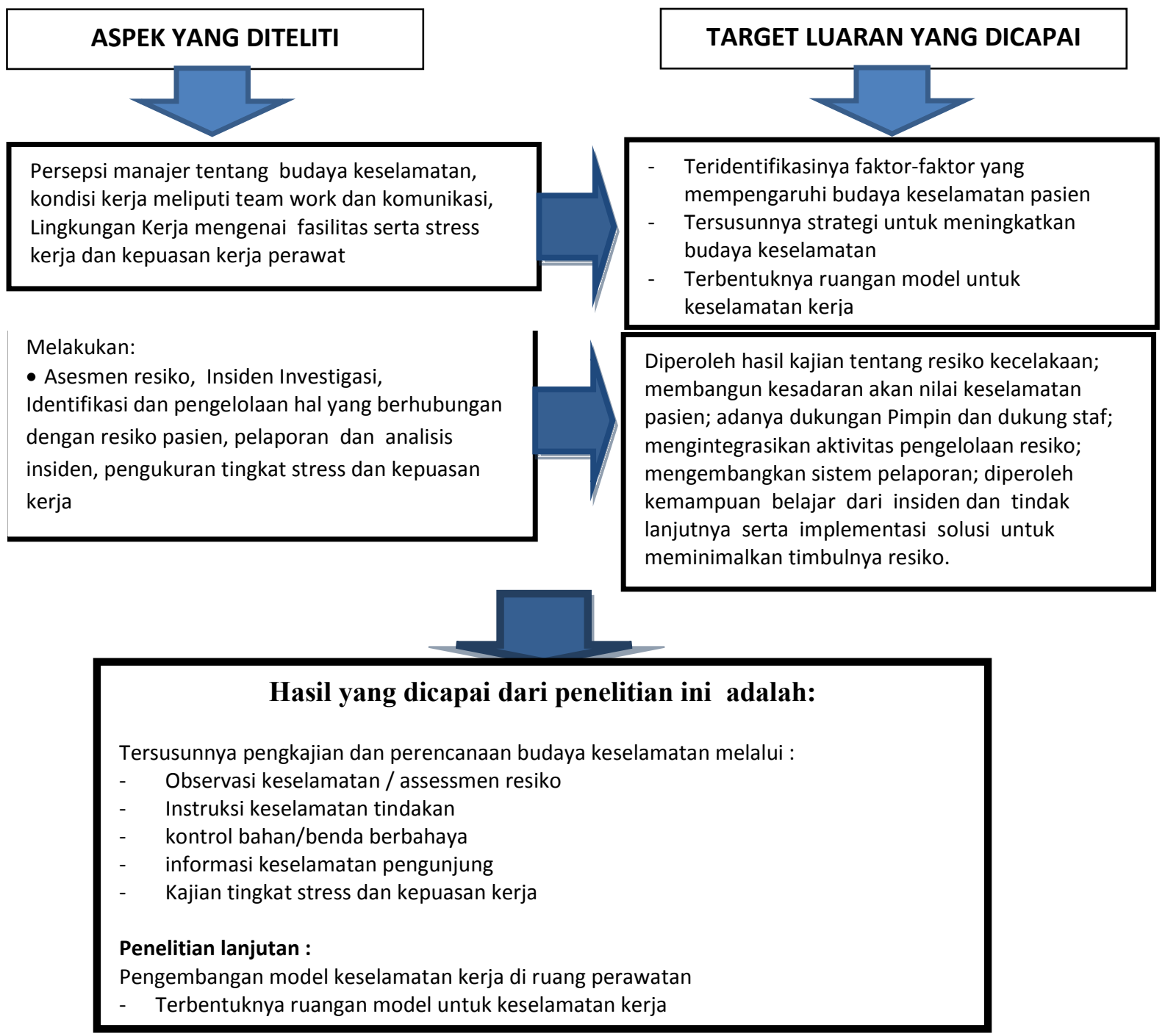


Lia Mulyati : Faktor Determinan yang Memengaruhi Budaya Keselamatan Pasien di RS

\section{Metode Penelitian}

Penelitian ini merupakan penelitian survei analitik dengan desain penelitian cross sectional. Sampel dalam penelitian ini sebanyak 88 perawat RS Pemerintah Kabupaten Kuningan. Instrumen penelitian menggunakan quesioner yang diadopsi dari Safety Attitudes Questionnary (SAQ) yang dikembangkan oleh Sexton et al., (2006), yang terdiri dari 6 dimensi yaitu; iklim tim kerja (teamwork climate), iklim keselamatan (safety climate), persepsi manajemen, kepuasan kerja, kondisi kerja, dan stres. Analisis data menggunakan Chi-Square untuk bivariat dan Regresi Logistik Ganda untuk multivariat.

\section{Hasil Penelitian}

Berdasarkan hasil penelitian diketahui bahwa sebagian besar $51,1 \%$ responden menyatakan bahwa tim kerja mendukung terhadap budaya keselamatan pasien, sementara 58\% memiliki persepsi yang baik terhadap manajemen RS dan $61,4 \%$ menyatakan stres, $67 \%$ responden menyatakan kondisi kerjanya kurang baik, namun sebagian besar $84,1 \%$ responden menyatakan puas terhadap pekerjaan yang dijalaninya saat ini. Sebagian besar 65,9\% responden menyatakan budaya keselamatan kerja di Rumah Sakit Pemerintah Kabupaten Kuningan kurang baik (tabel 1).

Dari 45 responden menunjukan bahwa tim kerja yang mendukung sebagian besar 57,8\% memiliki budaya keselamatan pasien yang baik sementara 43 responden yang merasa tim kerjanya kurang mendukung 90,7\% memiliki budaya keselamatan pasien yang kurang baik. Berdasarkan hasil analisis didapatkan nilai $\mathrm{p}$ 0.0005 dan nilai odd rasio 13,34 pada CI $95 \%$ $(4,1-43,72)$.

Dari 51 responden yang memiliki persepsi yang baik terhadap manajemen 54,9\% (28 orang) memiliki budaya keselamatan pasien yang baik dan 45,1\% memiliki budaya keselamatan pasienyangkurangbaiksementara dari 37 responden yang memiliki persepsi yang kurang baik terhadap manajemen $94,6 \%$ memiliki budaya keselamatan pasien kurang

Tabel 1 GambaranTim Kerja, Persepsi Perawat terhadap Manajemen, Stres Kerja, Kondisi Kerja, Kepuasan Kerja dan Budaya Keselamatan Pasien

\begin{tabular}{lcc}
\hline \multicolumn{1}{c}{ Variabel } & Frekuensi & Persentase \\
\hline Tim Kerja & & \\
Mendukung & 45 & 51.1 \\
Kurang Mendukung & 43 & 48.9 \\
Persepsi Perawat Terhadap Manajemen & & \\
Baik & 51 & 58 \\
Kurang Baik & 37 & 42 \\
Stress & & \\
Stress & 54 & 61.4 \\
Tidak Stress & 34 & 38.6 \\
Kondisi Kerja & & \\
Baik & 29 & 33 \\
Kurang Baik & 59 & 67 \\
Kepuasan Kerja & & \\
Puas & 74 & 84.1 \\
Kurang Puas & 14 & 15.9 \\
Budaya Keselamatan Pasien & & \\
Baik & 30 & 34.1 \\
Kurang Baik & 58 & 65.9 \\
\hline
\end{tabular}


Lia Mulyati : Faktor Determinan yang Memengaruhi Budaya Keselamatan Pasien di RS

Tabel 2 Distribusi Responden Berdasarkan Tim Kerja, Persepsi terhadap Manajemen, Stres Kerja, Kondisi Kerja dan Kepuasan Kerja terhadap Budaya Keselamatan Pasien

\begin{tabular}{|c|c|c|c|c|c|c|c|c|}
\hline \multirow[t]{3}{*}{ Variabel } & \multicolumn{4}{|c|}{ Budaya Keselamatan Pasien } & \multirow{2}{*}{\multicolumn{2}{|c|}{ Total }} & \multirow{3}{*}{$\begin{array}{c}\text { OR } \\
(95 \% \mathrm{CI})\end{array}$} & \multirow[t]{3}{*}{ P Value } \\
\hline & \multicolumn{2}{|c|}{ Baik } & \multicolumn{2}{|c|}{ Kurang } & & & & \\
\hline & $\mathbf{n}$ & $\%$ & $\mathbf{n}$ & $\%$ & $\mathbf{n}$ & $\%$ & & \\
\hline \multicolumn{9}{|l|}{ Tim Kerja } \\
\hline Mendukung & 26 & 57.8 & 19 & 42.2 & 45 & 100 & \multirow{2}{*}{$\begin{array}{c}13.34 \\
(4.1-43.72)\end{array}$} & \multirow[t]{2}{*}{$0.0005 *$} \\
\hline Kurang Mendukung & 4 & 9.3 & 39 & 90.7 & 43 & 100 & & \\
\hline \multicolumn{9}{|c|}{ Persepsi Terhadap Manajemen } \\
\hline Baik & 28 & 54.9 & 23 & 45.1 & 51 & 100 & \multirow{2}{*}{$\begin{array}{c}21.3 \\
(4.6-98.19)\end{array}$} & \multirow[t]{2}{*}{$0.0005 *$} \\
\hline Kurang Baik & 2 & 5.4 & 35 & 94.6 & 37 & 100 & & \\
\hline \multicolumn{9}{|l|}{ Stres } \\
\hline Tidak Stres & 18 & 52.9 & 16 & 47.1 & 34 & 100 & \multirow{2}{*}{$\begin{array}{c}3.94 \\
(1.55-9.98)\end{array}$} & \multirow[t]{2}{*}{$0.006 *$} \\
\hline Stres & 12 & 22.2 & 42 & 77.8 & 54 & 100 & & \\
\hline \multicolumn{9}{|l|}{ Kondisi Kerja } \\
\hline Baik & 8 & 27.8 & 21 & 72.4 & 29 & 100 & \multirow{2}{*}{$\begin{array}{c}0.641 \\
(0.24-1.69)\end{array}$} & \multirow[t]{2}{*}{$0.507 *$} \\
\hline Kurang Baik & 22 & 37.3 & 37 & 62.7 & 59 & 100 & & \\
\hline \multicolumn{9}{|l|}{ Kepuasan Kerja } \\
\hline Puas & 30 & 40.5 & 44 & 59.5 & 74 & 100 & & \multirow[t]{2}{*}{$0.002 *$} \\
\hline Kurang Puas & 0 & 0 & 14 & 0 & 14 & 100 & & \\
\hline
\end{tabular}

Tabel 3 Hasil Analisis Pemodelan Multivariate Regresi Logistik Ganda ; Tim Kerja, Persepsi terhadap Manajemen, dan Stres Kerja

\begin{tabular}{lccccc}
\hline Variabel & B & $\boldsymbol{P}$-Wald & P-Value & OR & CI 95\% \\
\hline Tim Kerja & 2.235 & 10.542 & 0.001 & 9.346 & $2.43-36.02$ \\
Persepsi terhadap menajemen & 2.983 & 12.302 & 0.000 & 19.742 & $3.73-104.5$ \\
Stres kerja & 1.615 & 5.309 & 0.021 & 5.026 & $1.27-19.85$ \\
Konstanta & -4.752 & & & & \\
\hline
\end{tabular}

Tabel 4 Hasil Uji Interaksi; Tim Kerja dengan Stres Kerja, Persepsi terhadap Manajemen dengan Stres Kerja, Persepsi terhadap Manajemen dengan Tim Kerja, Kondisi Kerja dengan Kepuasan Kerja, Kondisi Kerja dengan Tim Kerja, Stres Kerja dengan Kepuasan Kerja

\begin{tabular}{lc}
\hline Interaksi Variabel & $\boldsymbol{P}$-Value \\
\hline Tim kerja dengan kepuasan kerja & 0.093 \\
Tim kerja dengan stress kerja & $0.0005^{*}$ \\
Persepsi terhadap manajemen dengan stress kerja & $0.0005^{*}$ \\
Persepsi terhadap manajemen dengan tim kerja & $0.0005^{*}$ \\
Kondisi kerja dengan kepuasan kerja & 0.219 \\
Kondisi kerja dengan tim kerja & 0.872 \\
Stress kerja dengan kepuasan kerja & 0.093 \\
\hline
\end{tabular}

* Signifikan terhadap alpha 0.005 
Lia Mulyati : Faktor Determinan yang Memengaruhi Budaya Keselamatan Pasien di RS

baik dan hanya $5.4 \%$ (2 orang) memiliki budaya keselamatan pasien yang baik, hasil analisis selanjutnya didapatkan nilai $\mathrm{p} 0.0005$ dengan odd rasio 21.3 CI 95\% (4.6 - 98.19).

Dari 54 responden yang merasakan adanya stres kerja sebagian besar $77.8 \%$ (54 orang) memiliki budaya keselamatan pasien yang kurang baik dan hanya $22.2 \%$ yang memiliki budaya keselamatan pasien yang baik. Sementara dari 34 responden yang tidak merasakan stres kerja 52.9\% memiliki budaya keselamatan kerja yang baik dan 47.1\% (16 orang) memiliki budaya keselamatan pasien yang kurang baik, dan hasil analisis lanjutan didapatkan nilai $\mathrm{p} 0.006$ dengan odd rasio 3.94 CI 95\% (1.55 -9.98).

Dari 59 responden yang merasakan kondisi kerja kurang baik sebagian besar $62.7 \%$ memiliki budaya keselamatan pasien yang kurang baik dan hanya $37.3 \%$ memiliki budaya keselamatan pasien yang baik, sementara dari 29 responden $72.4 \%$ memiliki budaya keselamatan pasien yang kurang baik dan hanya 27.8\% memiliki budaya keselamatan pasien yang baik. Berdasarkan analisis lanjutan di dapatkan nilai p 0.507 dengan odd rasio 0.641 CI $95 \%(0.24-1.69)$.

Dari 74 responden yang memiliki kepuasan kerja yang baik 59.5\% memiliki budaya keselamatan pasien yang kurang baik dan hanya $40.5 \%$ memiliki budaya keselamatan pasien yang baik dan dari 14 responden yang memiliki kepuasan kerja yang baik, seluruhnya $100 \%$ memiliki budaya keselamatan kerja yang kurang baik dan dari hasil analisis lanjutan di temukan nilai p 0.002 (tabel 2).

Hasil analisis multivariat yang menjadi faktor determinan yang mempengaruhi budaya keselamatan pasien adalah tim kerja dengan nilai $\mathrm{p}$ 0.001, setelah dikontrol oleh persepsi terhadap manajemen dan stres kerja, persepsi terhadap manajemen dengan nilai p 0.000 setelah dikontrol tim kerja dan stres kerja dan stres kerja dengan nilai p 0.021 setelah dikontrol tim kerja dan persepsi terhadap manejemen, dan yang menjadi factor penentu adalah persepsi terhadap manajemen dengan nilai p 0.000 dengan odd rasio 19.742 (tabel 3).

Berdasarkan tabel 4 di atas dapat diketahui bahwa terdapat tiga variabel yang signifikan berinteraksi yaitu tim kerja dengan stres kerja, persepsi terhadap manajemen dengan stres kerja, dan persepsi terhadap manajemen dengan tim kerja.

Berdasarkan analisis multivariate dengan menggunakan regresi logistik ganda, maka di dapatkan persamaan sebagai berikut :

$\mathrm{y}=$ konstanta $+\mathrm{a} 1 \mathrm{x} 1+\mathrm{a} 2 \mathrm{x} 2+\ldots \ldots \ldots . . . \mathrm{aixi}$

$y=-4.752+2.235$ (tim kerja) +2.983 (persepsi terhadap manajemen) +1.615 (stres kerja)

Persamaan ini dapat diaplikasikan untuk memprediksi probabilitas budaya keselamatan pasien dengan menggunakan rumus:

$$
p=1 /\left(1+e^{-y}\right)
$$

Di mana:

$\mathrm{p}=$ probabilitas untuk terjadinya suatu

kejadian

$\mathrm{e}=$ bilangan natural $=2.7$

$\mathrm{y}=$ konstanta $+\mathrm{a} 1 \mathrm{x} 1+\mathrm{a} 2 \mathrm{x} 2+\ldots \ldots \ldots . . . \mathrm{aixi}$

$a=$ nilai koofisien tiap variabel

$\mathrm{x}=$ nilai variabel bebas

Berdasarkan hasil test Hosmer dan Lameshow didapatkan p-value $0.955>$ dari alpha 0.05 artinya persamaan yang diperoleh mempunyai kalibrasi yang baik dengan AUC (area under curve) $91.1 \%$ artinya persamaan ini memiliki kemampuan diskriminasi yang sangat kuat/ sangat memuaskan.

\section{Pembahasan}

Hasil penelitian ditemukan sebagian besar $65.9 \%$ (58 orang) perawat memiliki budaya keselamatan pasien yang kurang baik. Data tersebut menunjukan bahwa kemungkinan terjadi kesalahan atau kejadian yang tidak diharapkan pada pasien yang di rawat di Rumah Sakit Pemerintah Kuningan masih tinggi.

Kejadian yang tidak diharapkan atau kejadian nyaris cedera bukan hanya saja kesalahan dari faktor manusianya/kelalaian petugas pemberi pelayanan namun terdapat faktor lain yang memberikan kontribusi sehingga terjadi kejadian yang merugikan pasien, seperti yang di kemukakan oleh Reason. J.T dalam (Reason J.T et al., 2008) tentang Swiss Chees Model yang menggambarkan proses terjadinya kecelakaan melalui ilustrasi potongan-potongan keju Swiss. Terdapat empat lapisan yang menyusun terjadinya suatu kejadian kecelakaan, yaitu: organizational 
Lia Mulyati : Faktor Determinan yang Memengaruhi Budaya Keselamatan Pasien di RS

influences (pengaruh pengorganisasian dan kebijakan manajemen dalam terjadinya kecelakaan, unsafe supervision (pengawasan yang tidak baik), precondition for unsafe act (kondisi yang mendukung munculnya aktivitas yang tidak aman).

Gaya kepemimpinan demokratik merupakan gaya kepemimpinan yang di gunakan oleh pimpinan rumah sakit pemerintah Kabupaten Kuningan dan memiliki struktuk organisasi dengan garis komunikasi yang jelas, sehingga tidak ada kesulitan dalam mengkomunikasikan permasalahan khususnya isu-isu tentang keselamatan pasien, namun masih di rasakan adanya budaya shaming and blaming sehingga ada kekhawatiran dalam pelaporan kejadian yang tidak diharapkan dan kejadian nyaris cedera, sehingga jika hal tersebut terjadi hanya menjadi perbincangan atau diatasi pada level manajerial dimana kejadian terjadi, hanya kejadian-kejadian tertentu yang dilakukan pelaporan namun tidak pernah ada umpan balik. Manajemen rumah sakit sudah memiliki komitmen dalam meningkatkan budaya keselamatan pasien namun belum tersosialisasi secara menyeluruh ke setiap karyawan.

Hal yang paling dirasakan mempengaruhi keselamatan pasien adalah precondition for unsafe act (kondisi yang mendukung munculnya aktivitas yang tidak aman), dimana ditemukan keterbatasan peralatan yang dibutuhkan dalam melakukan asuhan keperawatana, beban kerja perawat yang cukup tinggi serta metode asuhan yang digunakan masih bersifat fungsional sehingga kontroling pelaksanaan asuhan tertumpu pada kepala ruangan. Kondisi tersebut sangat erat kaitannya dengan kebijakan yang diambil pihak manajemen.

Menurut Ardern \& Jane (2012), budaya keselamatan pasien dipengaruhi oleh 3 faktor utama yaitu; 1) Sikap dan perilaku (senior management, middle management, supervisor, karyawan, keselamatan dan kesehatan yang representatif serta komitmen anggota komite), 2) lingkungan; (tipe organisasi, finansial, jenis pekerjaan yang dilakukan, desain pekerjaan, kecepatan kerja, pelatihan yang tersedia, garis komunikasi, 3) sistem; (proses pelaporan kejadian/insiden yang mengancam keselamatan pasien, proses audit, proses inventigasi, komunikasi dan sistem umpan balik). Berdasarkan hal tersebut untuk menciptakan budaya keselamatan pasien maka seluruh lapisan mulai dari komitmen pimpinan sampai karyawan harus dibenahi. Studi penelitian telah menunjukan bahwa kepemimpinan yang baik mempunyai hubungan yang signifikan dengan perilaku keamanan kerja yang lebih baik dan menurunkan angka kecelakaan serta meningkatkan kepatuhan terhadap keselamatan (Katz-Navon et al., 2005). Sebuah penelitian lain di Inggris mengungkapkan bahwa persepsi staf tentang efektivitas kepemimpinan manajer senior memiliki hubungan dengan menurunnya keluhan pasien dan meningkatnya kepemimpinan klinik (Shipton et al, 2008).

Berdasarkan hasil penelitian ditemukan fakta bahwa tim kerja yang mendukung sebagian besar $(57.8 \%)$ memiliki budaya keselamatan pasien yang baik sementara responden yang merasa tim kerjanya kurang mendukung (90.7\%) memiliki budaya keselamatan pasien yang kurang baik. Berdasarkan hasil analisis bivariat tim kerja memiliki hubungan yang signifikan dengan budaya keselamatan pasien ( $p$-value 0.0005 ) dan nilai odd rasio 13.34 artinya tim kerja yang mendukung berpeluang sebesar 13 kali lebih besar dalam terciptanya budaya keselamatan pasien.

Di Rumah Sakit Pemerintah Daerah Kuningan 51.13\% merasakan memiliki tim kerja yang mendukung, hal tersebut ditunjang oleh factor homogenitas budaya yang sebagian besar berasal dari suku sunda dan dan jenjang pendidikan dengan $82 \%$ perawat telah mengikuti program pendidikan sarjana keperawatan, hal ini dapat meminimalisir stres budaya akibat perbedaan nilai dan norma, serta pola berfikir perawat dalam pencapaian tujuan asuhan keperawatan akan memiliki kesepahaman, sehingga dapat meminimalkan friksi yang dapat menimbulkan gangguan pada atmosfer kerja tim.

Di Rumah Sakit Pemerintah Daerah Kuningan perbedaan profesi dalam satu tim tidak terlalu banyak hanya profesi perawat, dokter dan gizi dengan jumlah tim yang sedikit, serta persepsi mengenai konsep kerja sama dalam tim di masing-masing profesi masih sama, yaitu saling memenuhi kebutuhan atau saling melengkapi dalam 
Lia Mulyati : Faktor Determinan yang Memengaruhi Budaya Keselamatan Pasien di RS

pemberian asuhan pada pasien. Aktivitas kolaborasi antar profesi masih belum tampak dilakukan karena masing-masing profesi masih berorientasi pada tugas atau peran dan fungsinya bukan asuhan yang berfokus pada pasien, sementara menurut Baerg Krista, et al. (2012), pelayanan yang berpusat pada pasien (Patient-Centered Care) merupakan pelayanan yang diunggulkan untuk menjawab isu-isu perkembangan penyakit kronis, oleh karena itu kemampuan bekerja sama dalam tim, komunikasi dan saling memahami tugas dan tanggung jawab antar profesi merupakan hal yang penting dimiliki oleh seluruh anggota tim pemberi pelayanan kesehatan.

Tim kerja yang baik juga sangat didukung oleh pola komunikasi yang efektif, kesamaan persepsi terhadap tujuan tim, serta kesamaan norma dan nilai-nilai yang di anut organisasi. Dalam dunia kesehatan, tim kerja dan kerja sama tim bergantung pada seberapa banyak perbedaan profesi dalam pengaturan kerja. Menurut Flin et al, (2006), terdapat 3 faktor utama yang mempengaruhi tim kerja yaitu; 1) pemimpin/ketua tim (pengetahuan, keterampilan, sikap, gaya kepemimpinan dan personality), 2) anggota tim (pengetahuan, keterampilan, sikap personality), 3) struktur tim (jumlah/ukuran tim, norma-norma yang berlaku, status, dan keterpaduan). Ketiga faktor tersebut akan menciptakan dinamika kerja yang kondusif atau tidak kondusif yang merupakan hasil keterbangunan dari komunikasi, koordinasi, kerja sama, managemen konflik dan pengambilan keputusan dalam tim.

Menurut Baker et al.,(2003), tim kerja yang buruk dapat menyebabkan kematian atau pada umumnya membahayakan pasien, sementara tim kerja yang baik dapat meningkatkan perawatan. Beberapa hasil penelitian lain tentang perawatan menunjukan bahwa tim kerja, komunikasi dan kepemimpinan merupakan hal yang penting dalam menjaga keselamatan pasien (Scott-Cawiezel \& Vogelsmeier, 2006).

Manser (2008), mengungkapkan beberapa temuan berdasarkan literature review; terdapat tiga penelitian yang mendukung hubungan antara tim kerja dengan keselamatan pasien adalah; 1) penelitian yang menginvestigasi faktor-faktor yang berkontribusi terhadap insiden/ kejadian yang tidak diharapkan, penelitian ini menunjukan bahwa tim kerja berperan penting dalam mencegah dan menyebabkan kejadian yang tidak diharapkan; 2) penelitian tentang persepsi pemberi pelayanan kesehatan terhadap tim kerja; (a) persepsi tim kerja dan perilaku keselamatan pasien yang relevan dengan perilaku tim memiliki hubungan dengan kualitas perawatan dan keselamatan pasien, (b) persepsi tim kerja dan gaya kepemimpinan yang dihubungkan dengan kepuasan staff yang berdampak pada peningkatan kemampuan klinik dalam penyediaan pelayanan pasien yang aman; 3) studi observasi perilaku tim kerja dengan penampilan klinik yang baik.

Berdasarkan pemodelan regresi logistik ditemukan bahwa tim kerja merupakan faktor determinan budaya keselamatan pasien setelah dikontrol oleh persepsi terhadap manajemen dan stres kerja dengan odd rasio 9.346 yang menunjukan bahwa individu yang memiliki dukungan yang baik dari tim kerja memiliki peluang sebesar 9.346 kali lebih besar untuk memiliki budaya keselamatan pasien yang baik.

Tim kerja merupakan hal yang fundamental dalam peningkatan kualitas asuhan dan budaya keselamatan pasien karena tim kerja yang akan memberikan warna terhadap atmosfer kerja, oleh karena itu pimpinan atau pihak manajemen RS perlu memastikan efektifitas dan kondusivitas tim kerja. Selain itu untuk menciptakan budaya keselamatan kerja maka harus ada upaya yang sinergi antara pimpinan, ketua tim dan anggota tim yang berinteraksi langsung dengan pasien.

Manajemen rumah sakit memiliki pengaruh yang cukup besar dalam peningkatan kinerja karyawan, khususnya perawat. Berdasarkan hasil penelitian ditemukan bahwa sebagian besar 58\% perawat memiliki persepsi yang baik terhadap pihak manajemen. Persepsi yang baik dari karyawan terhadap pihak manajemen dapat terbangun dari hasil interaksi positif yang terjadi antara karyawan dengan pihak manajemen baik top level manager maupun middle level manager, selain itu persepsi yang baik juga dapat terbentuk dari kesesuaian antara tuntutan pihak manajemen dengan harapan karyawan.

Berdasarkan hasil penelitian ditemukan terdapat hubungan antara persepsi terhadap manajemen dengan budaya keselamatan 
Lia Mulyati : Faktor Determinan yang Memengaruhi Budaya Keselamatan Pasien di RS

pasien dengan nilai $\mathrm{p}$ 0.0005. Dalam membangun budaya keselamatan pasien diperlukan komitmen bersama dalam melakukan asuhan kepada pasien bebas dari injuri/kejadian yang tidak diharapkan dan tertuang dalam visi dan misi organisasi, sehingga upaya-upaya dalam meningkatkan atau menciptakan budaya keselamatan pasien terintegrasi di setiap aspek proses kerja. KanzNavon et al., (2005), menemukan fakta bahwa ketika budaya keselamatan menjadi prioritas top level manager, unit-unit pelayanan rumah sakit mengalami lebih sedikit kesalahan dalam pelaksanaan asuhan. Shipton et al., (2008) dalam penelitiannya menunjukan adanya relevansi antara persepsi staff terhadap efektivitas kepemimpinan manager yang dikaitkan dengan menurunnya angka keluhan pasien dan tingkat penguasaan klinik yang lebih baik.

Proses untuk embangun persepsi yang baik para pimpinan/manajer harus menunjukan komitmen mereka tentang keselamatan pasien, dengan kata lain para pimpinan harus menjadi role model, setiap perilakunya harus menunjukan upaya keselamatan pasien. Selain itu salah satu faktor dalam menciptakan budaya keselamatan pasien adalah pelaporan kejadian insiden/kondisi yang tidak diharapkan serta adanya system umpan balik, kondisi ini belum membudaya di instansi-instansi pelayanan kesehatan karena ada faktor ketakutan atau kekhawatiran atau bahkan menganggap insiden merupakan aib petugas kesehatan yang harus ditutupi. Budaya belajar dari kesalahan dan tidak melakukan pelebelan/blaming terhadap petugas yang melakukan kesalahan harus ditunjukan oleh pimpinan.

Berdasarkan pemodelan regresi logistik pesepsi terhadap manajemen merupakan factor determinan dan merupakan factor yang paling dominan setelah dikontrol oleh tim kerja dan stres kerja mempengaruhi budaya keselamatan pasien dengan odd rasio 19.742 artinya individu yang memiliki persepsi yang baik terhadap managemen memiliki peluang 19.742 lebih besar untuk berkontribusi terciptanya budaya keselamatan pasien.

Berdasarkan hasil tersebut persepsi karyawan terhadap manajemen memiliki pengaruh paling besar dalam membangun budaya keselamatan pasien, untuk mencapai tujuan secara optimal, manajer/pimpinan harus bersinergi dengan karyawan di berbagai lapisan, oleh karena itu model kepemimpinan yang paling sesuai adalah model kepemimpinan transformasional. Kepemimpinan transformasional adalah sebuah peroses dimana pimpinan dan para bawahannya berusaha untuk mencapai tingkat moralitas dan motivasi yang lebih tinggi, hal ini berbeda dengan model kepemimpinan transaksional untuk memotivasi agar bawahan melakukan tanggungjawab mereka, para pemimpin transaksional sangat mengandalkan pada sistem pemberian penghargaan dan hukuman kepada bawahannya (Givens J.R. 2008).

Penerapan model kepemimpinan transformasional memiliki dampak baik pada tingkat organisasi maupun tingkat individu. Menurut Bass et al., (2003), kepemimpinan transformasional memiliki 4 dimensi yaitu; 1) idealized influence (pengaruh ideal), 2) inspirational motivation (motivasi inspirasi), 3) intellectual stimulation (stimulasi intelektual). 4) individualized consideration (konsiderasi individu), dengan kata lain pemimpin transformasional harus dapat dijadikan panutan (dikagumi, dihormati dan dipercaya), mampu menggugah spirit tim dalam organisasi, mampu menumbuhkan ide-ide baru, memberikan solusi yang kreatif terhadap permasalahan-permasalahan yang dihadapi bawahan, dan memberikan motivasi kepada bawahan untuk mencari pendekatan-pendekatan yang baru dalam melaksanakan tugas-tugas organisasi, serta mau mendengarkan dengan penuh perhatian masukan-masukan bawahan dan memperhatikan kebutuhan-kebutuhan bawahan akan pengembangan karir.

Hasil penelitian menemukan fakta bahwa $61,4 \%$ mengalami stres kerja dan sebagian besar 77.8\% memiliki budaya keselamatan pasien yang kurang baik dan hanya 22.2\% yang memiliki budaya keselamatan pasien yang baik. Sementara responden yang tidak merasakan stres kerja sebanyak $38.8 \%$, $52.9 \%$ memiliki budaya keselamatan kerja yang baik dan hanya $47.1 \%$ memiliki budaya keselamatan pasien yang kurang baik.

Kekurangan tenaga baik sebagai tim pelayanan kesehatan maupun tenaga penunjang merupakan hal yang paling sering dikeluhkan oleh perawat. Tuntutan tugas 
Lia Mulyati : Faktor Determinan yang Memengaruhi Budaya Keselamatan Pasien di RS

pelaksanaan asuhan terhadap pasien dan tugas administratif serta menangani complain pasien dan keluarga merupakan sumber kelelahan kerja dan stres kerja perawat di rumah sakit pemerintah Kabupaten Kuningan, oleh karena itu diakui oleh pihak rumah sakit mahasiswa praktikan diberdayakan untuk melakukan asuhan terhadap pasien. Tumpang tindih antara tugas struktural maupun fungsional juga dikeluhkan oleh sebagian besar kepala ruangan.

Kondisi stres seseorang ditentukan oleh keseimbangan antara tutuntutan yang ditujuka (seperti beban kerja) terhadap sumber daya yang dimiliki individu untuk mengatasi tuntutan tersebut (seperti pengalaman, keterampilan), ketika tuntutan yang diterima melebihi kemampuan yang dimiliki maka akan menimbulkan kondisi yang tidak menyenangkan seperti; kecemasan atau perasaan tidak sehat, kurang konsentrasi atau perasaan mudah marah (Cooper et al, 2001). Stres kerja juga dapat bersumber dari tim kerja yang tidak saling mendukung serta kondisi kerja yang kurang baik. Pada penelitian ini ditemukan sebagian besar responden (67\%) menyatakan kondisi kerjanya kurang baik dan $(48.9 \%)$ merasakan tim kerja kurang mendukung.

Berdasarkan hasil penelitian stres kerja memiliki hubungan yang signifikan dengan budaya keselamatan keselamatan pasien dengan nilai p 0.0006 dan odd rasio 3.94, dapat diinterpretasikan bahwa perawat yang tidak stres memiliki peluang 3.94 kali berkontribusi terciptanya budaya keselamatan pasien yang baik. Menurut Farquharson et al, (2012) stres yang dialami oleh perawat dapat menurunkan kondisi kesehatan fisik, psikologis, mengurangi kepuasan kerja, meningkatkan angka ketidakhadiran kerja karena sakit, meningkatnya turnover staf dan buruknya penampilan kerja. Menurut Aiken et al., (dalam Farquharson 2012), tingkat stres dan beban kerja yang tinggi menyebabkan kurang optimalnya asuhan keperawatan yang diberikan pada pasien, meningkatnya angka pelanggaran terkait dengan keselamatan pasien, dan terjadinya kesalahan yang lebih sering (cognitive failure).

Pada kondisi saat ini di era pemerintah memberlakukan jaminan kesehatan serta adanya perkembangan demografi masyarakat (baik dari jumlah maupun IPM) maka tuntutan untuk peningkatan kualitas pelayanan yang diberikan semakin tinggi, hal tersebut dapat menjadi salah satu sumber stres dan meningkatnya beban kerja pada perawat, oleh sebab itu dukungan dari pimpinan/manajemen rumah sakit sangat diperlukan dengan melakukan pengaturan sumber daya manusia disetiap ruang rawat harus disesuaikan baik jumlah maupun kualifikasi perawat yang dibutuhkan, serta manajemen melakukan sistem kontrol dan umpan balik yang baik. Tidak hanya dukungan dari pihak manajemen yang mempengaruhi stres perawat namun dukungan tim kerja juga merupakan factor penting yang mempengaruhi kondisi stres perawat, hal tersebut sejalan dengan analisis lanjutan pada penelitian ini yang menemukan adanya interaksi yang signifikan antara persepsi perawat terhadap manajemen dan tim kerja dengan stres kerja.

Cooper \& Clarke (2003), menyatakan bahwa reaksi individu terhadap stres pada gilirannya dapat menyebabkan gejala stres dalam organisasi: seperti pergantian staf tinggi atau ketidakhadiran yang meningkat akibat sakit. Stres di tempat kerja juga sangat berkaitan dengan keselamatan kerja: seperti tingkat kecelakaan. Penelitian yang dilakukan oleh Departemen kesehatan UK (2011 dalam Farquharson et al., 2012), menemukan fakta bahwa $30 \%$ perawat menyatakan mengalami stres dalam melaksanakan pekerjaannya dalam satu tahun terakhir, 34\% sering berfikir keluar dari pekerjaannya saat ini, dan $16 \%$ akan meninggalkan pekerjaannya jika dia telah menemukan pekerjaan lain.

Berdasarkan uraian di atas upaya penurunan stres kerja perlu ditangani secara serius, hal tersebutdapatdilakukan secarainternal(dengan penerapan manajemen koping yang adaptif) maupun eksternal yang berhubungan dengan pihak manajerial yaitu dengan menyesuaikan antara beban kerja dengan penyediaan sumber daya manusia, memberikan kesempatan atau memfasilitasi karyawan untuk meningkatkan kemampuan baik kognitif maupun psikomotor, meningkatkan kuantitas dan kualitas peralatan yang mendukung pelayanan serta meningkatkan iklim kerja yang kondusif.

Hasil penelitian menemukan bahwa sebagian besar 67\% (59 orang) menyatakan bahwa kondisi kerja mereka kurang baik, 
Lia Mulyati : Faktor Determinan yang Memengaruhi Budaya Keselamatan Pasien di RS

dan hanya 33\% (29 orang) yang menyatakan baik. Hasil analisis bivariat ditemukan bahwa kondisi kerja tidak memiliki hubungan yang signifikan terhadap budaya keselamatan pasien, pada penelitian ini didapatkan nilai p $0.507>\alpha 0.05$ dengan odd rasio 0.64 . Kondisi kerja dapat diartikan sebagai kualitas lingkungan kerja dan dukungan logistik seperti sumber daya, peralatan yang diperlukan untuk operasional pelaksanaan asuhan dan pedokumentasian serta sistem informasi yang diperlukan. Pada penelitian ini kondisi kerja yang di eksplorasi adalah penyedian/ peningkatan kualitas sumberdaya manusia, kedisiplinan perawat dan rasa tanggungjawab dalam pelaksanan asuhan yang menjunjung tinggi nilai budaya keselamatan pasien.

Berdasarkan analisis jawaban yang disampaikan oleh perawat, pihak manajemen RS sudah cukup melakukan peningkatan sumber daya manusia, kondisi ini bisa di lihat dalam bentuk pengikutsertaan perawat dalam berbagai pelatihan ataupun memberikan kesempatan untuk melanjutkan pendidikan ke jenjang yang lebih tinggi. Data lain menunjukan perawat memiliki anggapan bahwa supervise tentang kedisiplinan belum dilakukan secara rutin dan sebagian besar perawat menilai bahwa di areanya masih banyak personil yang tidak mematuhi aturan yang ditentukan serta keyakinan bahwa kejadian yang tidak diharapkan merupakan tanggung jawab perawat dan keterlibatan pihak manajemen masih sangat rendah.

Berdasarkan hal tersebut dapat dianalisis bahwa dalam upaya menciptakan budaya keselamatan pasien diperlukan adanya strategi peningkatan kesadaran perawat terhadap pentingnya penerapan asuhan pasien dengan menjunjung tinggi hak-hak pasien. Kondisi kerja yang kurang mendukung untuk pelaksanaan keselamatan pasien dapat dipengaruhi oleh jumlah dan kualitas sumberdaya manusianya dan fasilitas yang tersedia untuk pelaksanan asuhan terhadap pasien.

Hasil penelitian menemukan sebagian besar $84,1 \%$ menyatakan puas dengan pekerjaannya dan hanya $15,9 \%$ (14 orang) yang merasa kurang puas. Kepuasan kerja merupakan sikap emosional yang menyenangkan dan mencintai pekerjaannya. Sikap ini dicerminkan oleh moral kerja, kedisiplinan dan prestasi kerja.
Kepuasan kerja dapat dinikmati dalam pekerjaan, luar pekerjaan, dan kombinasi dalam dan luar pekerjaan. Kepuasan kerja merupakan salah satu faktor yang dapat mempengaruhi performa kerja. Pada penelitian ini ditemukan kepuasan kerja memiliki hubungan dengan budaya keselamatan pasien dengan nilai $\mathrm{p} 0.002<\alpha 0.05$.

\section{Simpulan}

Tim kerja, persepsi terhadap pimpinan, stres dan kepuasan kerja memiliki hubungan yang bermakna terhadap budaya keselamatan pasien. Persepsi terhadap pimpinan merupakan faktor determinan terciptanya budaya keselamatan pasien, oleh karena itu gaya kepemimpinan, teknik komunikasi serta kemampuan manajerial pimpinan merupakan suatu hal yang sangat perlu diperhatikan dalam menciptakan atmosfer kerja yang kondusif sebagai upaya untuk terciptanya budaya keselamatan pasien.

\section{Daftar Pustaka}

Ardern \& Jane. (2012). Creating a safety culture. Government of Western Australia: Department of Commerce, WorkSafe. Available at ww.commerce.wa.gov.au/ Worksafe/PDF/Forums/safety_culture-Jane_. pdf.

Baerg, K., et al. (2012). Survey of interprofesional collaboration learning needs and training interest in health professionals, teachers, and students: An exploratory study. Journal of Researchin Interprofesional Practice and Education (JRIPE), 2(2), 187200.

Baker, G etal.(2003). Patient Safety Leadership Walk Rounds . The Joint Commission Journal on Quality and Patient Safety, 29(1), 16-26(11) Bass, B., Avolio, B., Jung, D., et al. Predicting unit performance by assessing transformational and transactional leadership. Journal of Applied Psychology, 88(2), 207-218.

Colla, et al. (2005). Measuring patient safety climate: A review of surveys. Qual Saf Health 
Lia Mulyati : Faktor Determinan yang Memengaruhi Budaya Keselamatan Pasien di RS

Care, 14, 364-366.

Cooper. (2001). Towards a model of safety culture. Safety Science, 32(6), 111-136.

Cooper, C., \& Clarke, S. (2003) Managing the risk of workplace stress: Health and safety hazards. London: Routledge.

Farquharson, B., Cheryl, B., Derek, J., et al. (2012). Nursing stress and patient care: RealTime investigation of the effect of nursing tasks and demands on psychological stress, physiological stress, and job satisfaction performance: Study protocol. Jurnal of Advance Nursing.

Flin, Burns, Mearns, Yule, \& Robertson. (2006). Measuring safety climate in health care. Qual Saf Health Care, 15, 109-115.

Givens, J.R. (2008), Transformational leadership: The impact on organizational and personal outcomes. Emerging Leadership Journeys, 1(1), 4-24.

James, J.T. (2013). A new, evidence-based estimate of patient harms associated with hospital care. Journal of Patient Safety, 9, $122-128$.

Katz-Navon, T., Naveh, E., \& Stern, Z. (2005) Safety climate in healthcare organisations: A multidimensional approach. Academy of Management Journal, 48, 1075-1090.
Komite Keselamatan Rumah Sakit (KKP-RS) PERSI. (2007). Pedoman pelaporan insiden keselamatan pasien (IKP). Jakarta.

Manser, T. (2009) Teamwork and patient safety in dynamic domains of healthcare. A review of the literature. Acta Anesthesiology Scandinavia, 53, 143-151.

Reason, J. (2008). The human contribution: Unsafe acts, accidents and heroic recoveries.

Sexton, B.J., Helmreich, L.R., Neilands, B.T., et al. (2006). The safety attitudes questionnaire: Psychometric properties, benchmarking data, and emerging research. BMC Health Services Research, 6, 44.

Shipton, H., Armstrong, C., West, M., \& Dawson, J. (2008) The impact of leadership and quality climate on hospital performance. International Journal for Quality in Health Care, 6, 439-445.

Scott-Cawiezell, J., \& Vogelsmeier, A. (2006). Nursing home safety: A review of the literature. Annual Review of Nursing Research, 24, 179215.

World Health Organization. (2009). Human factors in patient safety review of topics and tools; report for methods and measures working. WHO. 